\title{
Erratum: Embryonic transcription is controlled by maternally defined chromatin state
}

Saartje Hontelez, Ila van Kruijsbergen, Georgios Georgiou, Simon J. van Heeringen, Ozren Bogdanovic, Ryan Lister \& Gert Jan C. Veenstra

Nature Communications 6:10148 doi: 10.1038/ncomms10148 (2015); Published 18 Dec 2015; Updated 5 Jul 2016

This Article contains an error in Fig. 7 that was introduced during the production process. In panel a, the label 'dx1' should read 'cdxl'. The correct version of the figure appears below. 
a
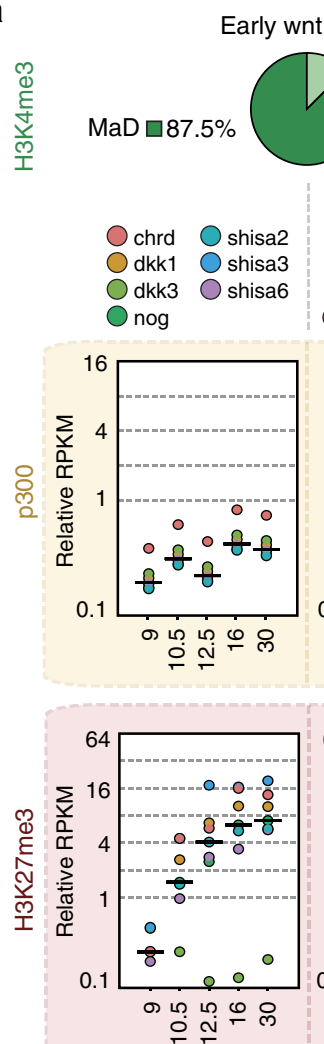

ZyD $\square 12.5 \%$

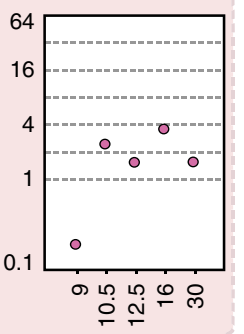

\section{cer1}

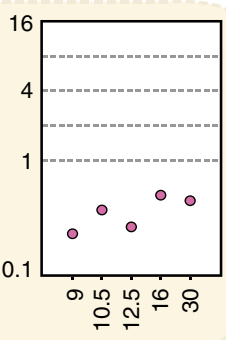

$20 \mathrm{~kb}$
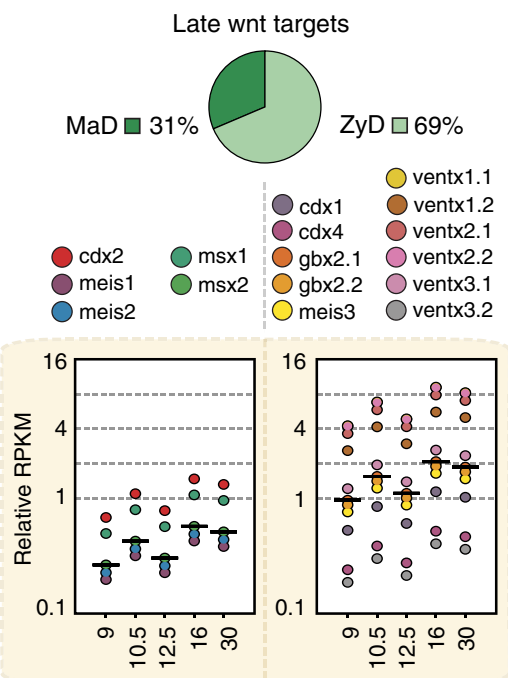

\section{b}
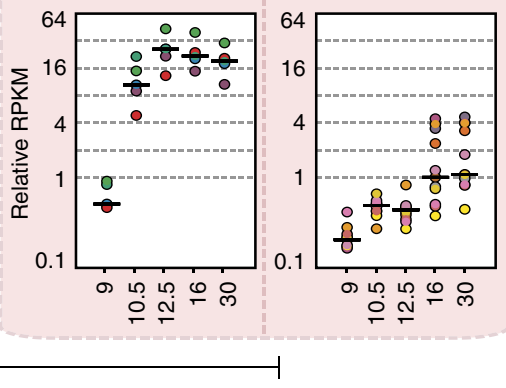

\section{Early Wnt, MaD} Stage $9 \mathrm{MeC}$ H3K4me3 st11 control H3K4me3 st11 $\alpha$-am.

p300 st11 control

p300 st11 $\alpha$-am

H3K27me3 st11 control H3K27me3 st11 $\alpha$-am.

RNAPII st9

RNAPII st $101 \frac{1}{2}$

RNAPII st11 control RNAPII st11 $\alpha$-am.

\section{Late Wnt, MaD}

Stage $9 \mathrm{MeC}$

H3K4me3 st11 control H3K4me3 st11 $\alpha$-am.

p300 st11 control

p300 st11 $\alpha$-am.

H3K27me3 st11 control H3K27me3 st11 $\alpha$-am. RNAPII st9

RNAPII st $101 / 2$

RNAPII st11 control

RNAPII st11 $\alpha$-am.

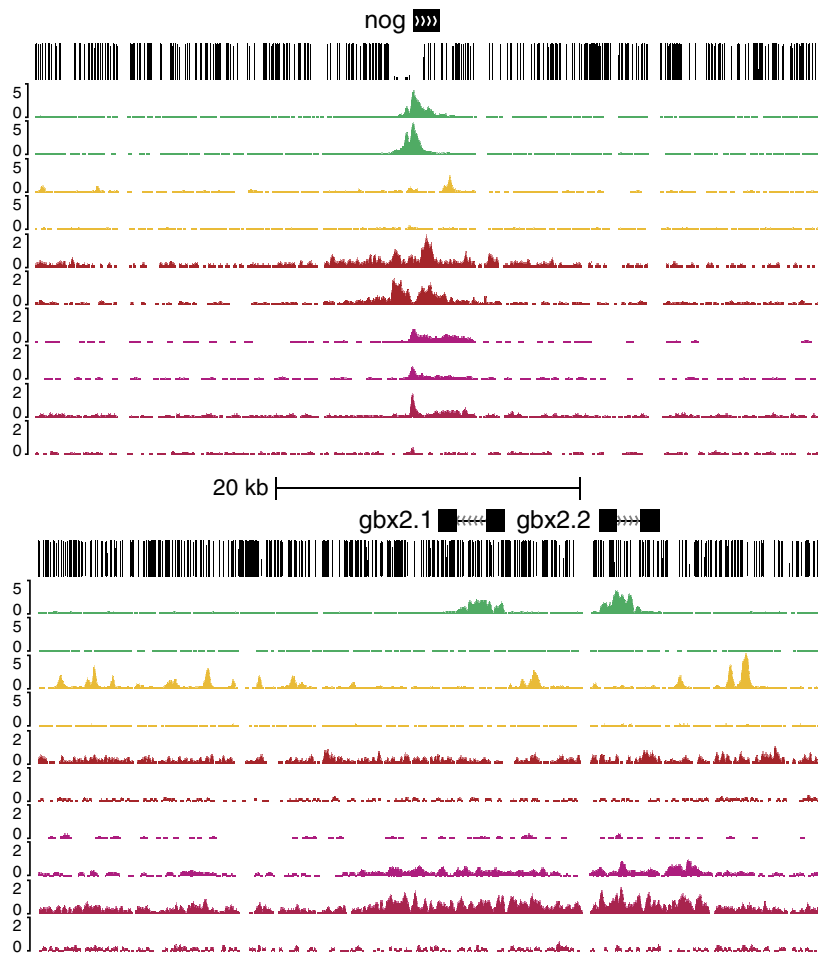

Figure 7

(c) (i) This work is licensed under a Creative Commons Attribution 4.0 International License. The images or other third party material in this article are included in the article's Creative Commons license, unless indicated otherwise in the credit line; if the material is not included under the Creative Commons license, users will need to obtain permission from the license holder to reproduce the material. To view a copy of this license, visit http://creativecommons.org/licenses/by/4.0/ 